Research Article

\title{
Multilevel Seismic Damage Behavior Correlation Analysis for RC Framed Structures
}

\author{
Jianguang Yue \\ College of Civil Engineering, Nanjing Tech University, Nanjing 211800, China \\ Correspondence should be addressed to Jianguang Yue; jgyue@njtech.edu.cn
}

Received 9 January 2018; Revised 17 March 2018; Accepted 1 April 2018; Published 10 May 2018

Academic Editor: João M. P. Q. Delgado

Copyright (c) 2018 Jianguang Yue. This is an open access article distributed under the Creative Commons Attribution License, which permits unrestricted use, distribution, and reproduction in any medium, provided the original work is properly cited.

Five structural levels, that is, material level, section level, member level, storey level, and structure level, were proposed to analyze the multilevel nonlinear mechanism of the reinforced concrete (RC) framed structures. Based on the presented deformation equivalent principle, a generalized stiffness damage model was developed for each structural level. At each structural level, the stiffness damage value can be calculated by the integration of the material stiffness damage. Furthermore, an impact factor was proposed to reflect the damage correlations between different structural levels. In order to verify this method, the proposed method was used to study the damage evolutions at various structural levels of a 12-storey frame structure. The numerical model utilizing the proposed analysis method produces results in good agreement with the test results of the 12storey frame structure. It shows that the proposed method is useful to assess the structure multilevel damage performance and to design a new structure.

\section{Introduction}

In damage mechanics of concrete structures, a damage model can directly calculate the inherent damage states of structures, members, or sections. For this reason, in the performance-based design method (PBDM), the damage degree is often evaluated in an explicit way by introducing the damage performance levels, which corresponds to the seismic intensity levels. The performance levels describe damage with the aid of damage models. However, in actual design works by now, the damage model is usually used to assess the nonlinear behavior for structure level or member level and very limitedly used in designing. The most important reason is that there is no any perfect damage model to describe the damage states for every structural level, and the damage correlations between the different levels are unknown. That is to say, it is not like the force-based design method which can clearly calculate the force relations between the structure level, storey level, member level, section level, and material level. Therefore, it is necessary to propose a new damage model which can calculate damage for every structural level and find a way to reflect the damage correlations between different structural levels.

For different analytical purposes, the damage model can be defined by different mechanical indicators, such as stiffness, deformation, energy, and vibration characteristics. For example, the hysteretic energy-based damage model is often used to evaluate the damage for structure level or member level $[1,2]$. In some researches, the deformation has been verified as a good damage indicator not only for the bending-failure-type members (RC columns, beams, and walls) but also for the shear-failure-type members [3]. The deformation-characterized interstorey drift ratio or plastic rotation was used to define the damage model by the study of Banon and Veneziano [4] and Wang et al. [5]. The widely-known Park and Ang damage model [6] was defined by both maximum displacement and plastic energy of dissipation. The strains of concrete and rebar were used to establish a procedure of damage determination for member level by Sharifi et al. [7]. Moreover, the bearing capacity of the M-N relationship can be used to evaluate the damage of section level [8], and the variations of the stiffness or intrinsic 


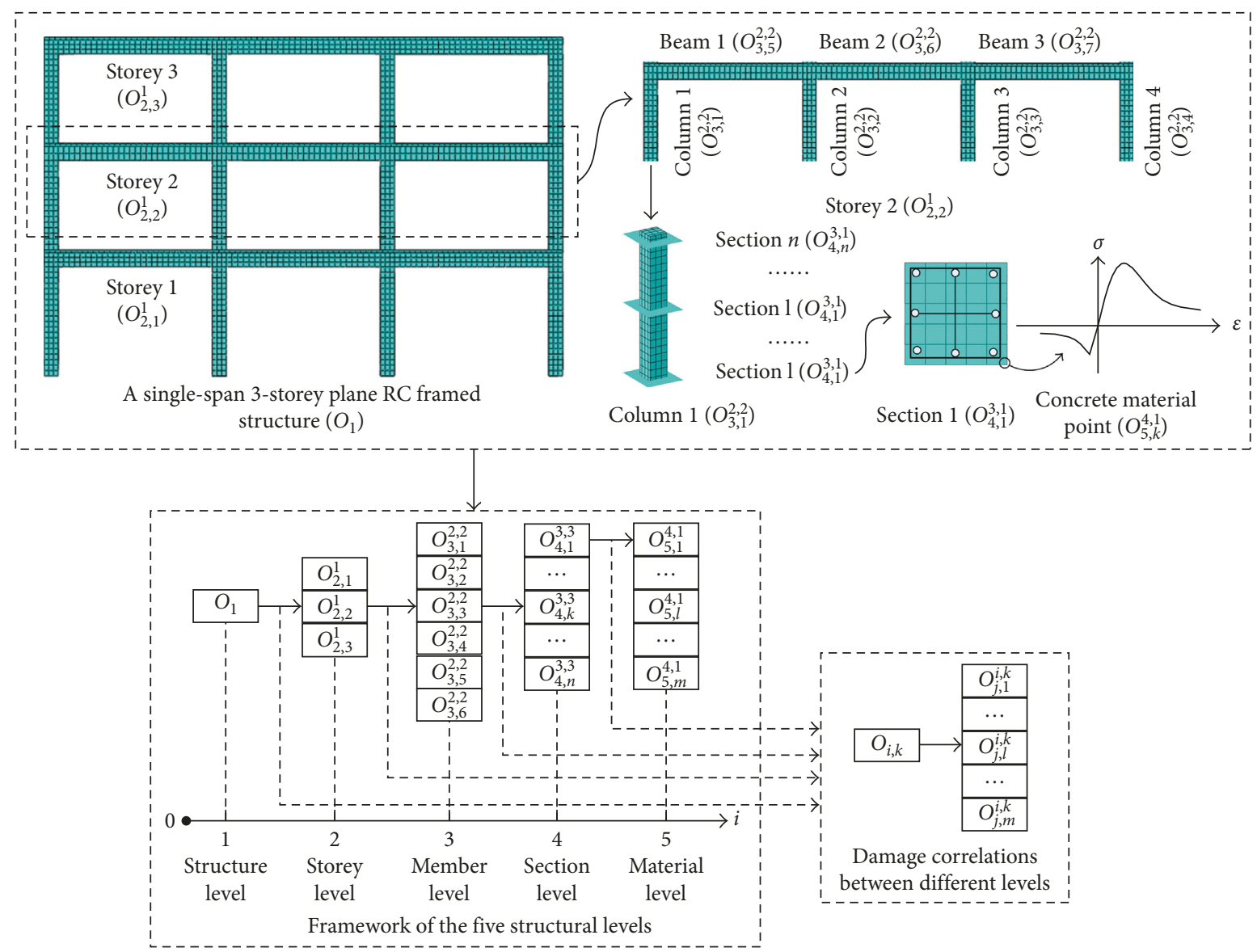

FIgURE 1: Illustration of multilevel damage definition.

period can be used to evaluate the damage of structure level [9].

In the theory of engineering mechanics, the stiffness means the deformation-resistant capacity, that is, the ratio of force to deformation, for any structural level. Thus, the stiffness could be an ideal damage indicator for the multilevel damage assessment. In fact, the stiffness-based damage index in a well-known concrete plastic-damage model [10] has been widely used for the nonlinear numerical analysis $[11,12]$. It was proposed from the strain equivalent principle [13] that the strain of damage material caused by nominal stress is equal to the strain of undamaged material caused by the effective stress. Furthermore, this stiffness-based damage index using the integrating method with the weight coefficient (such as the lengths or important factors of the damage zones) can be used to predict the damage performance of the structure level [14-16].

In this paper, a deformation equivalent principle was firstly proposed based on the strain equivalent principle. Secondly, a generalized stiffness-based damage model was presented for every structural level. Its arithmetic expression in an integrating form and the correlation impact factor were used to analyze the multilevel damage mechanism. As an example, a shaking table seismic test of a single-span 12storey RC framed structure was analyzed by the proposed method.

\section{Multilevels for RC Framed Structure}

Under earthquake seismic motion, the mechanical behaviorlike deformation capacity, bearing capacity of material, member, or structure can be characterized at material level, section level, member level, storey level, and structure level. As shown in Figure 1, each structural level can be expressed as the analysis object $O_{i}$, in which the letter $i$ means the structural level. The values of $i$ are $1,2,3,4$, and 5 for the structure level, storey level, member level, section level, and material level, respectively. An example for the multilevel definition is shown in Figure 1. In Figure 1, the subscript $i$ of $O_{i, k}$ denotes the structural level $i$ and the subscript $k$ is the object number; that is, $O_{i, k}$ means the object $k$ at level $i$, and $O_{1}$ means the object at structure level (the global structure). The superscript " $i, k$ " of $O_{j, l}^{i, k}$ means it is a part of $O_{i, k}$; that is, $O_{j, l}^{i, k}$ means the object $l$ at level $j$ as a part of $O_{i, k}$. As shown in Figure 1, the global structure is denoted as $O_{1}$ and storey 2 is denoted as $O_{2,2}^{1}$. In storey $2\left(O_{2,2}^{1}\right)$, the columns $1,2,3$, and 4 are denoted as $O_{3,1}^{2,2}, O_{3,2}^{2,2}$, $\mathrm{O}_{3,3}^{2,2}$, and $\mathrm{O}_{3,4}^{2,2}$, respectively, and the beams 1,2 , and 3 are denoted as $O_{3,5}^{2,2}, O_{3,6}^{2,2}$, and $O_{3,7}^{2,2}$, respectively. In column 1 $\left(O_{3,1}^{2,2}\right)$, section 1 can be written as $O_{4,1}^{3,1}$. The material point $k$ of section 1 is denoted as $O_{5, k}^{4,1}$.

According to the definition, the affiliation framework of the five structural levels is expressed in Figure 1. This 


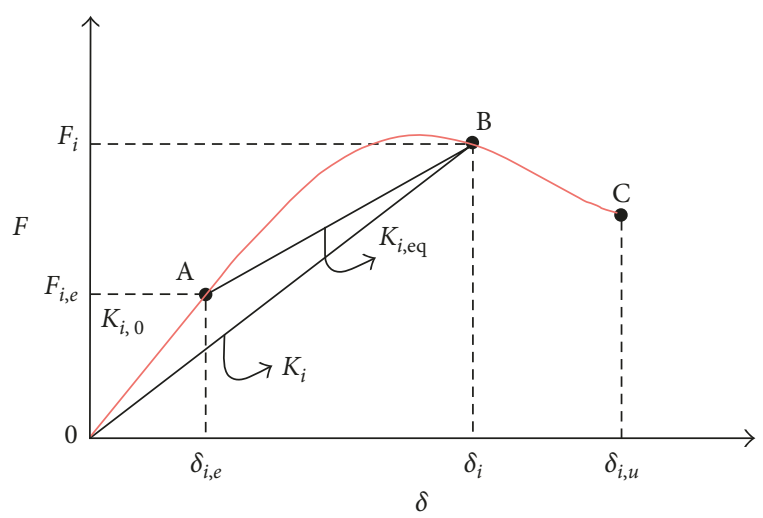

FIGURE 2: Generalized force-deformation relationship [17].

affiliation framework shows the analysis object for each structural level. It can be used to find which object is important for the structural mechanism. Moreover, the correlations between different levels can be abstractly expressed (Figure 1). It can represent the correlation between any two different structural levels.

\section{Deformation Equivalent Principle}

In general, local damage in RC structures subjected to a severe seismic motion is usually caused by the microcracking and crushing of concrete, yielding of the steel reinforcement, and bond deterioration of the steel-concrete interfaces. The local damage on a cross section can be adequately evaluated by the degradations of the sectional bending stiffness and moment bearing capacity. The overall combination of all local damages leads to the global stiffness and strength deterioration of the structure. Damage models are used to characterize the damage state of the structure after an earthquake seismic motion and can be used to assess the design aims or the postearthquake bearing capacity. According to the principle of strain equivalence, the damage at material level is defined by the concept of effective stress. The effective stress $\sigma^{\prime}$ is the stress applied on an element of undamaged material with the same deformation of a damaged element subjected to the current stress $\sigma$.

Essentially, the strain equivalence assumption describes the material stress-strain relation by introducing the damage variable $d$. Considering this principle can be popularized to any structural level, the definition is reasonably deduced as follows: the effective force $F^{\prime}$ (Figure 2) applied to an element of undamaged object (material, cross section, member, storey, or structure level) will have same deformation like a damaged element subjected to the current force $F$ (Figure 2).

\section{Seismic Stiffness Damage Model}

Therefore, a generalized force-deformation relation [17], as shown in Figure 2, can be used to describe the behavior at any structural levels. In Figure 2, point A represents the initial damage state and curve $0 \mathrm{AB}$ represents the nonlinear behavior caused by material damage.

In Figure 2, $\delta$ is the generalized deformation for every structural level, and $\delta_{i}, \delta_{i, e}$, and $\delta_{i, u}$ represent the deformation, elastic limit deformation, and ultimate deformation of level $i$, respectively; $F$ is the generalized force which corresponds to the generalized deformation $\delta, F_{i}$ represents the force for damaged configuration, $F_{i, e}$ is the elastic limit bearing capacity; $K_{i, 0}, K_{i}$, and $K_{i \text {,eq }}$ are the initial stiffness, secant stiffness, and equivalent stiffness, respectively. The equivalent stiffness $K_{i \text {,eq }}$ represents the damage effect on stiffness of the undamaged configuration and is expressed as

$$
K_{i, \mathrm{eq}}=\frac{\delta_{i} K_{i}-\delta_{i, e} K_{i, 0}}{\delta_{i}-\delta_{i, e}} .
$$

Here, the point A in Figure 2 is assumed to represent the initial damage state. Therefore, based on the deformation equivalent principle, the generalized damage variable $d_{i}$ is

$$
d_{i}=1-\frac{K_{i, \mathrm{eq}}}{K_{i, 0}}
$$

Equation (2) is the generalized stiffness damage variable which can reflect the stiffness degradation for every structural level. This model can also be formulated in the material configuration for thermodynamically stable problems with no temperature time variation. Thus, the mathematical form for the free energy is assumed as $[18,19]$

$$
\begin{aligned}
\psi_{5}\left(\varepsilon, d_{5}\right) & =\left(1-d_{5}\right) \psi_{5}^{0}(\varepsilon)=\left(1-d_{5}\right)\left[\frac{1}{2 \rho_{0}} \varepsilon^{T} \sigma_{0}\right] \\
& =\left(1-d_{5}\right)\left[\frac{1}{2 \rho_{0}} \varepsilon^{T} E_{0} \varepsilon\right], \\
d_{5} & =1-\frac{E_{\mathrm{eq}}}{E_{0}} ; \quad E_{\mathrm{eq}}=\frac{\varepsilon E-\varepsilon_{0} E_{0}}{\varepsilon-\varepsilon_{0}}
\end{aligned}
$$

where $\psi_{5}$ and $\psi_{5}^{0}$ ( $i=5$ for material level) are the free energy of damaged material and undamaged material, respectively; $d_{5}$ is the material stiffness damage variable; $\varepsilon$ and $\varepsilon_{0}$ are the strain tensor and elastic limit strain tensor of material, respectively; $\sigma_{0}$ is the stress tensor of undamaged material; $\rho_{0}$ is the material density; and $E_{0}$ is the initial elastic modulus, $E_{\mathrm{eq}}$ is the equivalent modulus, $E$ is the secant stiffness. Specially, if $d_{5}=0$, then $\psi_{5}\left(\varepsilon, d_{5}=0\right)$ means the strain energy of undamaged material.

The potential energy $W_{i, k}^{p}$ of object $O_{i, k}$ can be obtained by integrating $\psi_{5}$ with mass through the volume of $O_{i, k}$ and expressed as

$$
W_{i, k}^{p}=\int_{V_{i, k}} \psi_{5} d m=\int_{V_{i, k}}\left(1-d_{5}\right) \psi_{5}^{0} \rho_{0} d V=\left(1-d_{5}\right) W_{i, k}^{p, 0},
$$

where $W_{i, k}^{p, 0}$ is the potential energy of undamaged object $O_{i, k}$ and $W_{i, k}^{p, 0}=\int_{V_{i, k}} \psi_{0} \rho_{0} d V$. Thus, the stiffness damage $d_{i, k}$ of $\mathrm{O}_{i, k}$ can be calculated from (4) and expressed as 


$$
\begin{aligned}
d_{i, k} & =1-\frac{W_{i, k}^{p}}{W_{i, k}^{p, 0}}=\frac{\int_{V_{i, k}} \psi_{5}^{0} d V-\int_{V_{i, k}}\left(1-d_{5}\right) \rho_{0} \psi_{5}^{0} d V}{\int_{V_{i, k}} \rho_{0} \psi_{5}^{0} d V} \\
= & \frac{\int_{V_{i, k}} d_{5} \rho_{0} \psi_{5}^{0} d V}{\int_{V_{i, k}} \rho_{0} \psi_{5}^{0} d V} \approx \frac{\sum_{e}^{i, k} d_{5} \psi_{5}^{0}}{\sum_{e}^{i, k} \psi_{5}^{0}},
\end{aligned}
$$

where $\sum_{e}^{i, k}$ means the summation for all elements of object $O_{i, k}$. Equation (5) shows that the stiffness damage $d_{i, k}$ for any structural level $i$ can be calculated by the material damage $d_{5}$.

If the damage $d_{j, l}$ and the free energy $\psi_{j, l}^{0}$ of object $O_{j, l}^{i, k}$ are known, it has the relationships of $\sum_{e}^{j, l} \psi_{5}^{0}=\psi_{j, l}^{0}$ and $\sum_{m} \psi_{j, l}^{0}=\sum_{e}^{i, k} \psi_{5}^{0}$. The damage $d_{i, k}$ of object $O_{i, k}(j>i)$ can be obtained by substituting these two above relationships into (5), and the resulting expression is as follows:

$$
d_{i, k}=\frac{\sum_{m} d_{j, l} \psi_{j, l}^{0}}{\sum_{m} \psi_{j, l}^{0}},
$$

where $\sum_{m}$ means the summation for total parts of $O_{i, k}$ and $m$ is the part number of $O_{i, k}$. Equation (6) shows that the damage $d_{i, k}$ can also be obtained by the summation of $d_{j, l}$ with the weighted coefficient $\psi_{j, l}^{0}$.

Therefore, an impact factor $\gamma_{i, k}^{j, l}$ is proposed here to calculate the damage effect from $O_{j, l}^{i, k}$ to $O_{i, k}$. Based on (6), its expression is

$$
\gamma_{i, k}^{j, l}=\frac{d_{j, l} \psi_{j, l}^{0}}{\sum_{m} d_{j, l} \psi_{j, l}^{0}},
$$

where $0 \leq \gamma_{i, k}^{j, l} \leq 1$, and the higher value of $\gamma_{i, k}^{j, l}$ means higher damage effect from $O_{j, l}^{i, k}$ to $O_{i, k}$.

\section{Test Model and Numerical Simulation}

A shaking table test of a 12-storey RC frame model (Figure 3) of the State Key Laboratory of Disaster Reduction in Civil Engineering in Tongji University [20] was used to verify the proposed analysis method of the damage correlations of different structural levels. The ABAQUS computer program [21] was used to perform numerical simulation of the test model which was subjected by the earthquake seismic motions. In the finite element model, the material behavior of concrete was described by the concrete plastic-damage model presented by Lubliner et al. [10], which can calculate the compression and tensile damage of concrete. The concrete was modeled by C3D8R elements which are 8-node linear brick elements with reduced integration and hourglass control. The material behavior of the steel reinforcement was described by an elastoplastic model with $1 \%$ strain hardening. The steel reinforcements were modeled by the T3D2 elements which are 2-node linear displacement truss elements and embedded in the concrete elements.
The 12-storey model frame structure has one single bay in the $X$ - or $Y$-direction, a total height of $3.6 \mathrm{~m}$ and a storey height of $0.3 \mathrm{~m}$. The plan and elevation views of the structure are shown in Figure 3. The compressive strength of concrete is from $5.74 \mathrm{MPa}$ to $8.20 \mathrm{MPa}$. The cross-sectional size of all columns and beams are $50 \times 60 \mathrm{~mm}$ and $30 \times 60 \mathrm{~mm}$, respectively. Reinforcement layouts are identical in all beams and columns. The yield strength and ultimate strength of rebar number 1 (nominal diameter is $2.11 \mathrm{~mm}$ ) are $390 \mathrm{MPa}$ and $560 \mathrm{MPa}$, respectively. The yield strength and ultimate strength of rebar number 2 (nominal diameter is $0.9 \mathrm{~mm}$ ) are $327 \mathrm{MPa}$ and $397 \mathrm{MPa}$, respectively. The average elastic modulus of concrete is $7.75 \times 10^{3} \mathrm{MPa}$.

Four earthquake seismic motions were used as the test loading input: (1) El-Centro waves, (2) Kobe waves, (3) Shanghai artificial waves, and (4) Shanghai bedrock waves. The range of the input peak acceleration was 0.090-0.904 g. The standard storey and top storey were subjected by additional masses of $19.4 \mathrm{~kg}$ and $19.7 \mathrm{~kg}$, respectively. Totally 54 loading cases were calculated and compared with the test results.

In loading case number 53, the values of input peak ground acceleration in $X$-, $Y$-, and $Z$-direction were $0.904 \mathrm{~g}$, $0.769 \mathrm{~g}$, and $0.452 \mathrm{~g}$ of EI-Centro waves, respectively. In loading case number 53, vertical cracks occurred at the ends of beams from storey 2 to 8 . The damages from storey 3 to 8 were most serious, where the maximum width of cracks was about $4 \mathrm{~mm}$ and plastic hinges appeared at the ends of beams. There was almost no damage from storey 11 to 12 .

As shown in Figure 4, the calculated acceleration responses of A2, AY2, A7, and AY7 of loading case number 53 were compared with the test results. The acceleration responses of A2 and A7 were along the $X$-direction, and the responses of AY2 and AY7 were along the $Y$-direction. The calculated results agreed well with the test results. It shows that the numerical model can depict the nonlinear seismic responses of the test model with well accuracy. The multilevel damage evolutions of the test model can be analyzed based on the numerical responses. In the following, the loading case number 53 was used to be analyzed with the proposed method.

\section{Multilevel Damage Analysis}

6.1. Structure Level and Storey Level. The structural final damage state of loading cases number 53 is shown in Figure 5(a). The abbreviation PEEQT stands for the equivalent plastic tensile strain which reflects the onset of cracks. According to (6), the stiffness damage evolutions can be calculated for each structural level. Thus, the calculated stiffness damage evolutions of the global structure and each storey (from storeys F2 to F12 in Figure 3) are shown in Figure 5(b). The letter F followed by the number 1 to 12 , denotes the floor or storey. The damage of storey F1 was close to zero, so it was not shown in Figure 5(b).

In Figure 5, the calculated damages from storeys F3 to F8 were the most serious with the maximum damage value of 0.8. The damage evolution curves show that damages at 


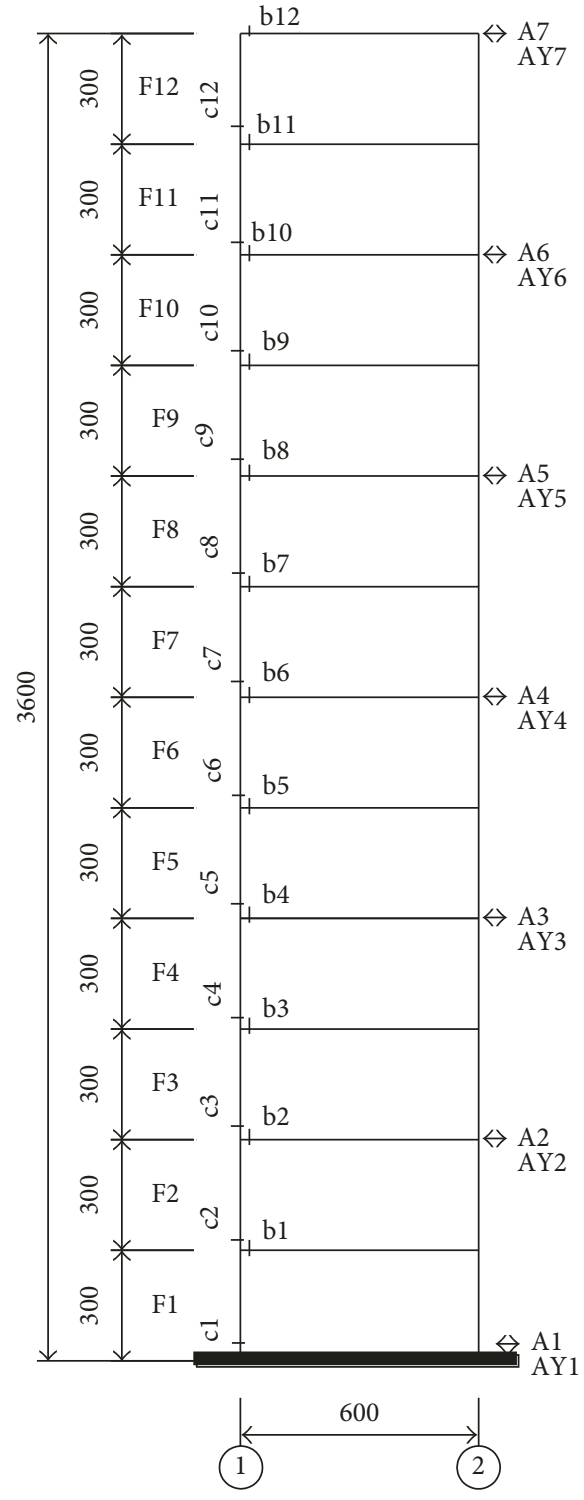

(a)

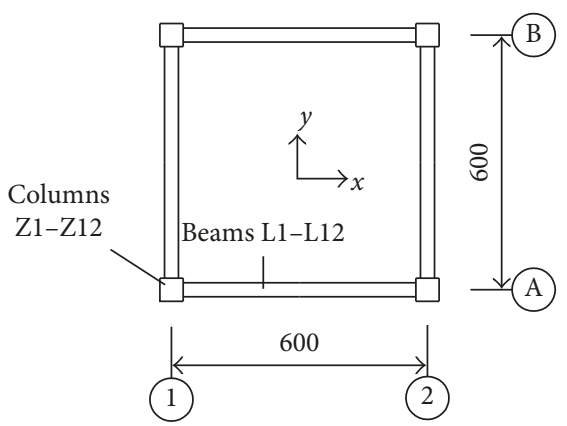

(b)

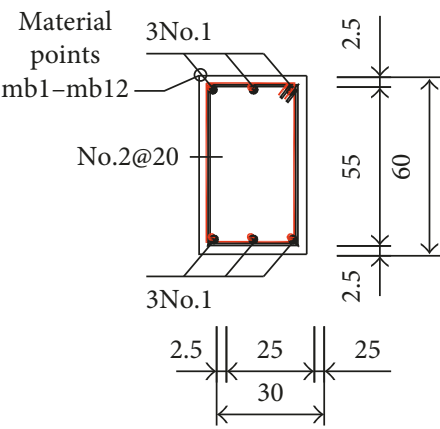

(c)

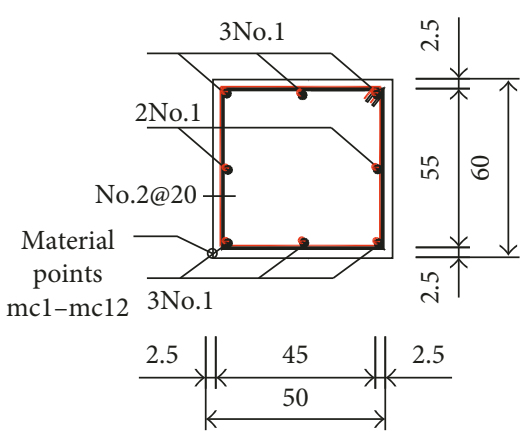

(d)

Figure 3: Geometrical details of the 12-storey RC frame test model [20]. (a) Elevation and acceleration sensor placement. (b) Structure plan. (c) Beam cross section. (d) Column cross section.

storeys F2 to F8 occurred almost at the same time. The calculated maximum damage of storey F2 was 0.5. The maximum damage value of the global structure was 0.7. Compared with the test damage states (Figure 5(a)), it shows that the calculated results were in good agreement with the test responses. Moreover, Figure 5(b) reflects the damage mechanism at storey level and structure level. The analysis results indicate that the structure level damage was mainly due to the damages of storeys F5 to F7.

6.2. Member Level, Section Level, and Material Level. The columns Z1 to Z12 ( $\mathrm{Z}$ means column) and beams B1 to B12 (B means beam) were analyzed for the member level. In Figure 6, if the damage value was close to zero, it will not be shown.
As shown in Figure 6(a), the onset of damage of columns $\mathrm{Z} 2$ and Z8 and beams from L2 to L8 started at the same time, that is, about $0.25 \mathrm{~s}$. The damage evolutions of beams from L3 to L7 developed faster than other members. At storey F2, the damage evolution of column Z2 developed faster than beam L2. At storey F8, the damage evolution of column Z8 developed faster than beam L8.

The maximum damage values of columns $\mathrm{Z} 2$ and $\mathrm{Z} 8$ were 0.6 and 0.8 , respectively. The maximum damage values of column Z2 and beams L3 to L7 were about 0.8. The maximum damage value of beam L8 was about 0.65 . The maximum damage values of column $\mathrm{Z} 2$ and beam $\mathrm{L} 2$ were about 0.5 .

According to Figure 6(a), the damages of storeys from F3 to F7 were mainly due to the beams, the damage of storey F8 


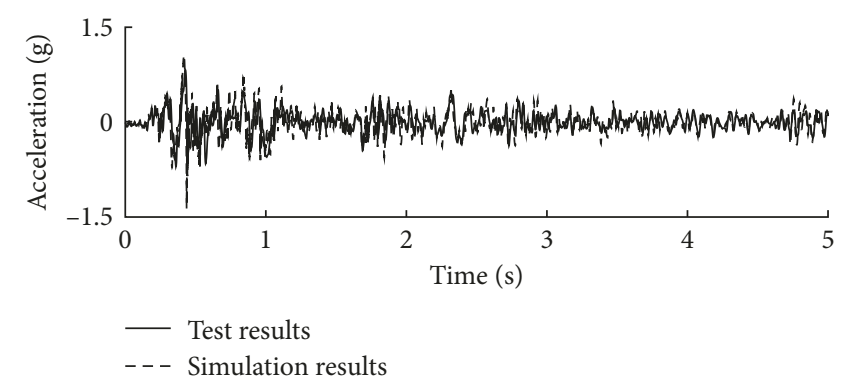

(a)

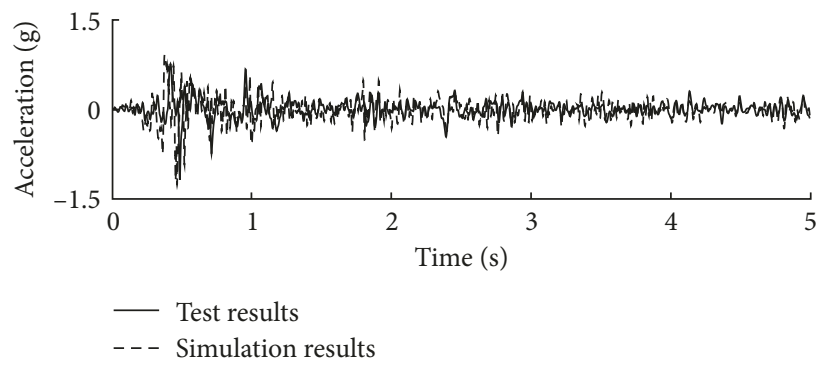

(c)

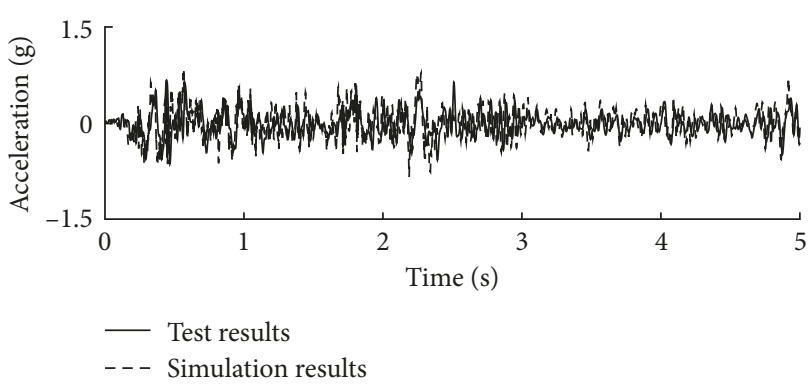

(b)

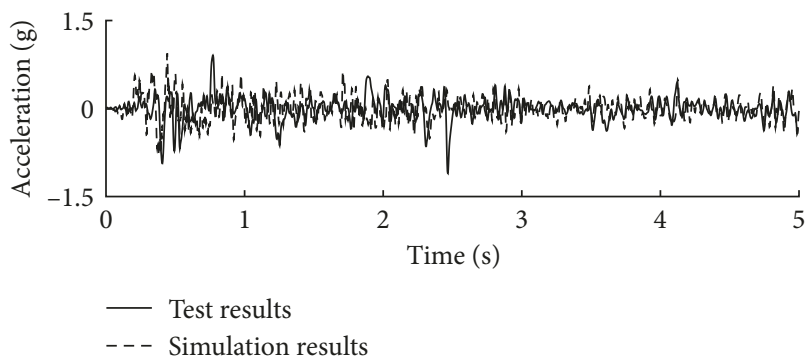

(d)

Figure 4: Comparisons of calculated and tests responses [20]. (a) Case 53: A2 acceleration comparison. (b) Case 53: AY2 acceleration comparison. (c) Case 53: A7 acceleration comparison. (d) Case 53: AY7 acceleration comparison.

was mainly due to the columns, and the damage of storey F2 was due to both columns and beams. Based on this analysis, only the sections of columns Z5 to Z7 and beams L5 to L7 were necessary to be analyzed for the section level (Figure 6(b)). In Figure $6(\mathrm{~b})$, the letters $c$ and $b$ mean the sections of column and beam, respectively.

Based on the comparison of Figures 5 and 6, it can be found that the damage of section level, member level, storey level, and structure level almost began at the same time (about $0.25 \mathrm{~s}$ ). The maximum damage values of sections $\mathrm{c} 5$, $c 6$, and c7 were small (about 0.3 ) which corresponded to the damage values of columns Z5, Z6, and Z7. The maximum damage values of sections b5, b6, and b7 were large (about 0.9 ) which corresponded to the damage values of beams L5, L6, and L7. Therefore, it means that the damages from storey F5 to F7 were mainly caused by the bending-type failures of beams.

Thus, only the material points mb5 to $\mathrm{mb} 7$ of beam sections L5 to L7 were necessary to be analyzed for material level (Figure 6(c)). It can be found that the damage of material level began at the same time with the other structural levels. However, the damages of mb5 and mb6 reached to their peak values earlier than mb7. The damage evolutions of material agreed with the responses of beams L5 and L6.

\section{Damage Correlation Analysis}

Although the multilevel damage analysis can respect the structural damage mechanism for different structural levels, it still cannot provide quantitative values to describe the correlations between different structural levels.
In this section, the damage correlations were analyzed to explore the inherent nonlinear behavior of the structure and to help designing a new structure. As mentioned above in Section 4, the presented impact factor $\gamma_{i, k}^{j, l}$ of (7) was used here to reflect the damage correlations quantitatively.

Firstly, the damage effect from storey level to structure level was analyzed (Figure 7(a)). It shows that the impact factor curves of sotreys F4, F5, and F6 started to increase at about $0.25 \mathrm{~s}$ and quickly reached to the peak values of 0.39 , 0.28 , and 0.18 , respectively, at about $0.5 \mathrm{~s}$. Then, the impact factor curves of F4, F5, and F6 began to decrease and finally reached to the minimum value of 0.11 , and meanwhile the structure reached to its maximum value. The impact factor curves of storeys F2, F3, F7, and F8 also started to increase at $0.25 \mathrm{~s}$ and reached to the maximum values of $0.19,0.15,0.12$, and 0.19 , respectively, while then began to decrease, and meanwhile the structure reached to the maximum value. It can be seen from the above results that the structure damage was caused by the storeys F4, F5, and F6 in the beginning and then caused by the storeys F2, F3, F7, and F8. Comparatively, the damage effect from storeys F5 and F6 was the most serious for the global structure. Thus, the damage effect from beam L5 and column Z5 to the storey F5 (Figure 8) was analyzed in the following (Figure 7(b)).

In Figure 7(b), the impact factor values of column Z5 were very close to zero. It indicates that column $\mathrm{Z} 5$ did not affect storey F5. While the impact factor curve of beam L5 started to increase at $0.25 \mathrm{~s}$ and reached to the maximum value of 0.25 , and meanwhile, the storey F5 reached to about half of its maximum value. It indicates that the damage of storey F5 was mainly caused by the beams. 
PEEQT

(Avg: $75 \%$ )

\begin{tabular}{|r|}
$+5.393 e-03$ \\
$+4.944 e-03$ \\
$+4.495 e-03$ \\
$+4.045 e-03$ \\
$+3.596 e-03$ \\
$+3.146 e-03$ \\
$+2.697 e-03$ \\
\hline \\
$+2.247 e-03$ \\
$+1.798 e-03$ \\
$+1.348 e-03$ \\
$+8.989 e-04$ \\
$+4.495 e-04$ \\
$+0.000 e+00$
\end{tabular}

Case 53

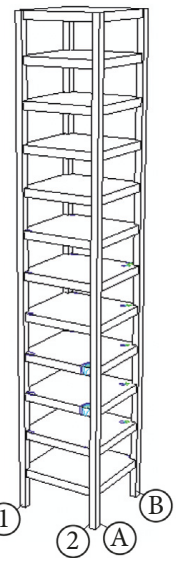

(B)

(a)

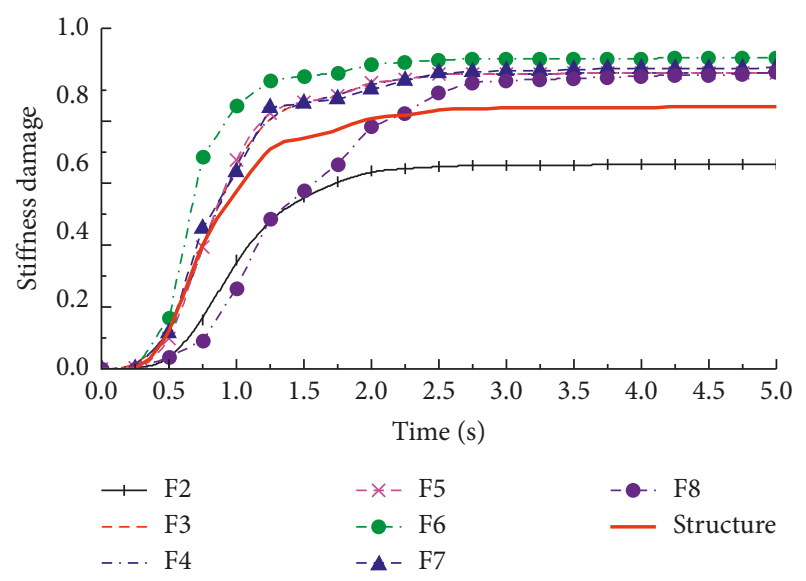

(b)

FIgURE 5: Damage results for structure level and storey level. (a) Final damage comparisons of calculation and test [20]. (b) Damage evolutions for storey level and structure level.

Furthermore, the damage effect from two cross sections (one is at the beam end and another is at the middle span in Figure 8) and one diagonal section (near the beam end in Figure 8) to beam L5 was analyzed as follows (Figure 7(c)).

It can be found that the impact factor values of sections b5-2 and b5-3 were close to zero while the maximum value of section b5-1 was 0.66 . That means the damage of beam L5 was mainly caused by the cross-sectional damage at its end which was the bending-type failure. Thus, three material fibers (Figure 8) were analyzed to reflect the damage effect from material points to the cross section b5-1. Here, each fiber, including three element nodes, was used as the representative for the material level. The impact factor curves of fiber 2 and fiber 3 were very close, and their values were larger than the value of fiber 1 . The impact factor maximum values of fiber 2 and fiber 3 were about three times of fiber 1. It indicates that the damage effect of the bottom fibers was more serious than the fibers at the top of the section.

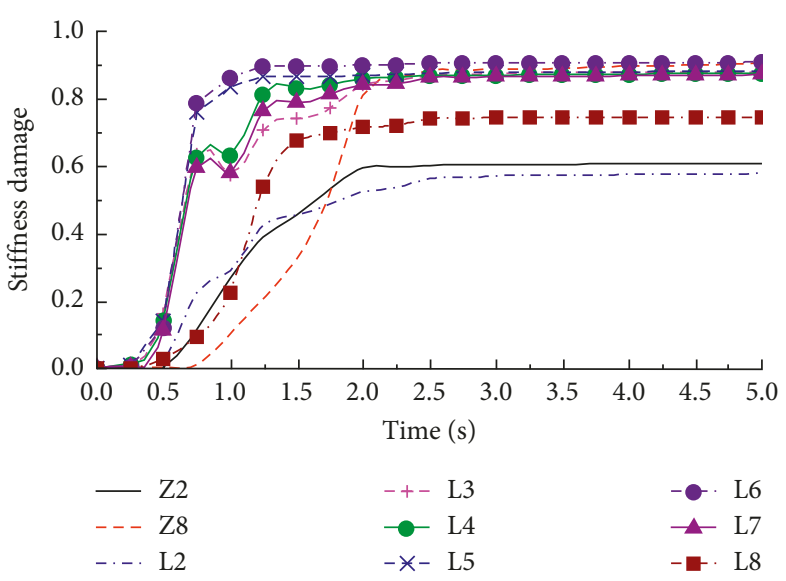

(a)

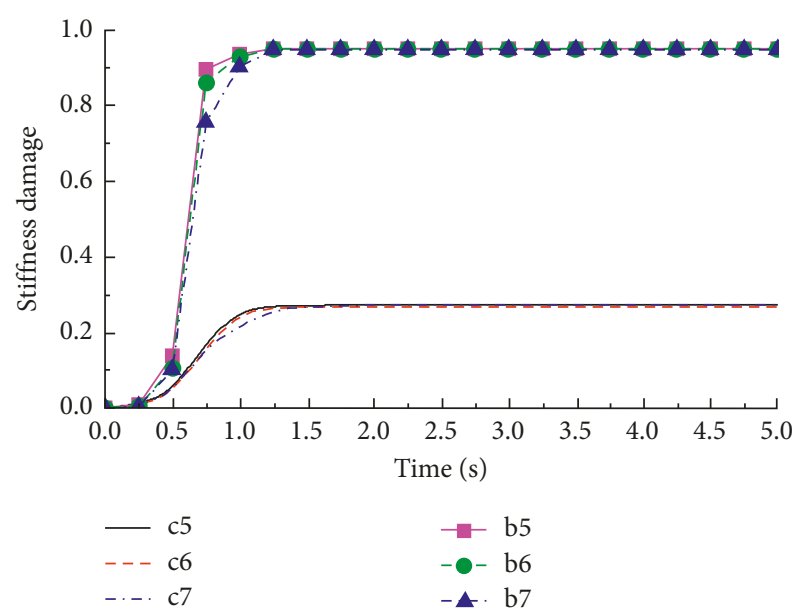

(b)

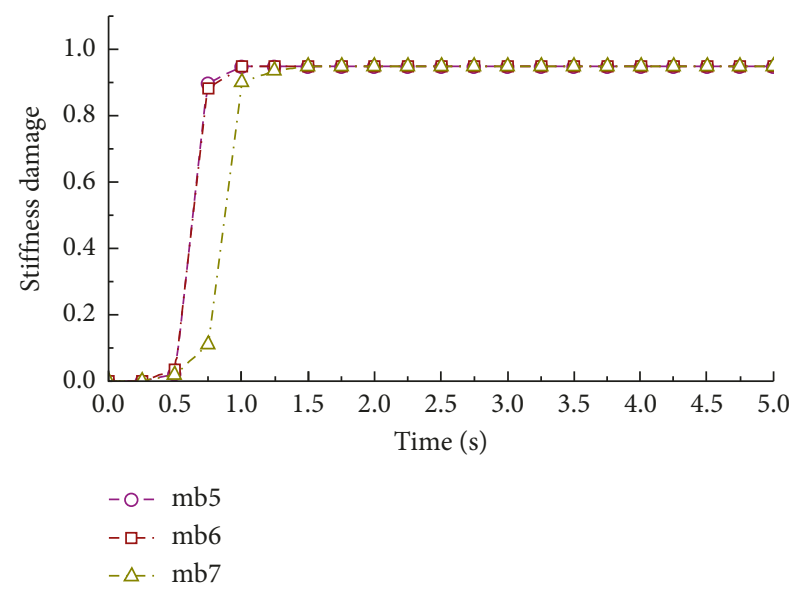

(c)

Figure 6: Damage evolutions for (a) member level, (b) section level, and (c) material level.

Based on the above analysis, the failure of this 12storey-framed structure model (noted as object $O^{1}$ ) was the plastic hinge failure mode of beams. The seriously damaged storeys were F5, F6, and F7 in which the damage effect from F5 (noted as $\mathrm{O}_{2,5}^{1}$ ) was the most serious. The damage of F5 was mainly due to the damage of beams which was mainly 


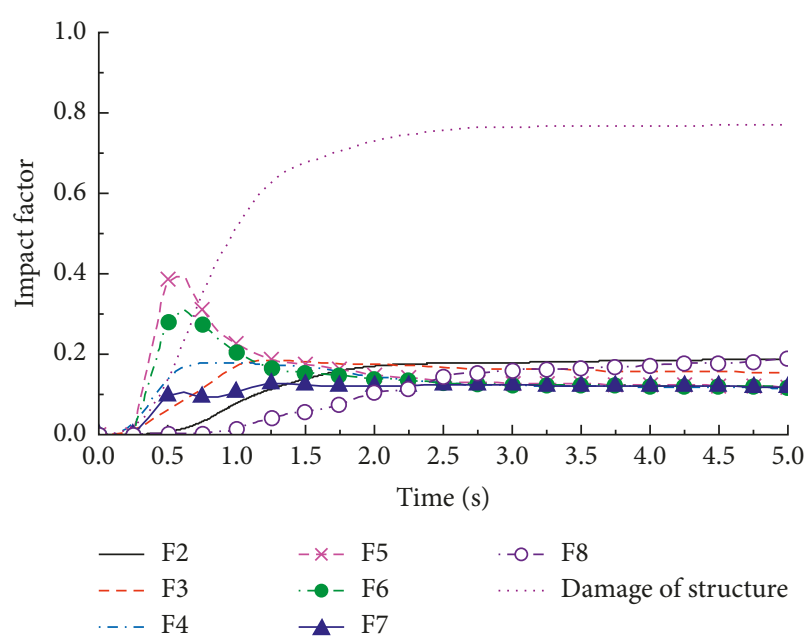

(a)

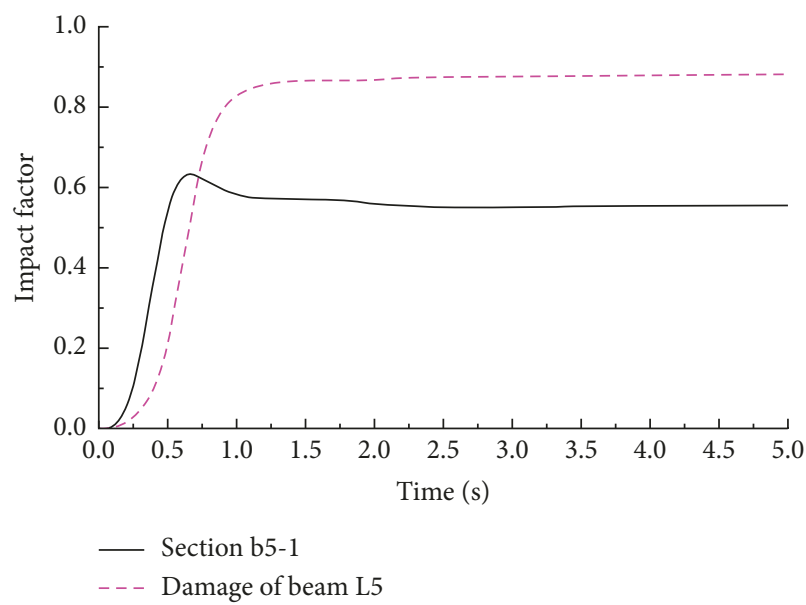

(c)

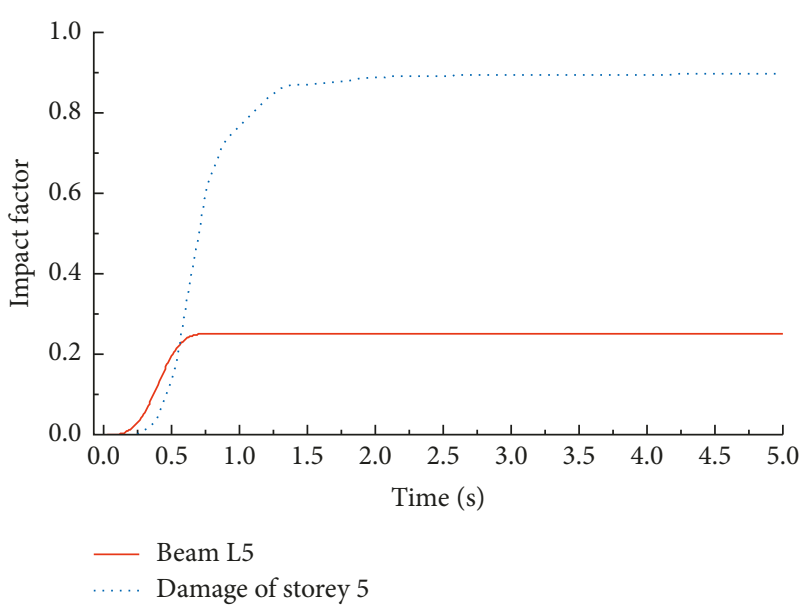

(b)

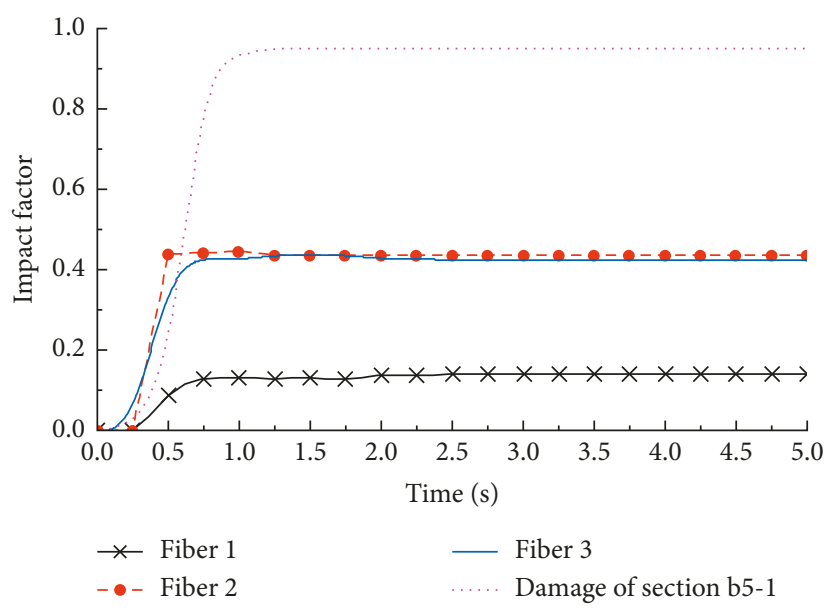

(d)

Figure 7: Damage correlations between different levels. (a) Storey level to structure level. (b) Member level to storey level. (c) Section level to member level. (d) Material level to section level.

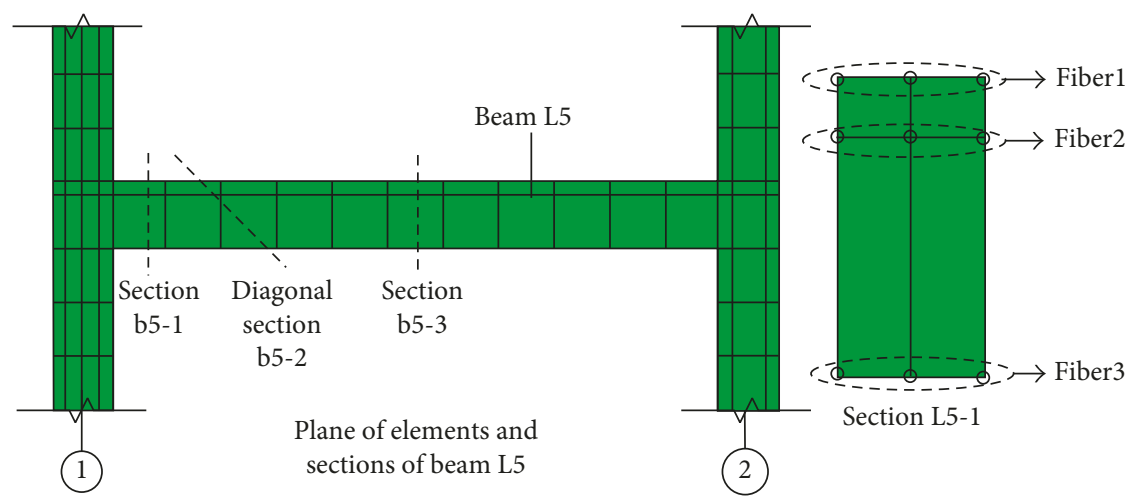

Figure 8: The analysis objects of member level, section level, and material level.

caused by the cross-sectional damage at the ends of the beam.

The impact factor values are listed in Table 1 . It represents qualitatively the damage effect between different structural levels. It shows the damage effect degree of the level $i$ comes from another level $j$. For example, about $12 \%$ damage of the global structure was caused by the storey F5, and about 25\% damage of storey F5 was caused by beam L5. Only 3\% damage of the global structure was caused by beam L5, and only $1.7 \%$ damage of the global structure was caused by the section L5-1. It can be seen that the damage mechanism of the structure can be described very clearly in 
TABLE 1: Damage correlations between different structural levels at limit state.

\begin{tabular}{lccccc}
\hline Structural level & Structure & $\begin{array}{c}\text { Story } \\
\text { F5 }\end{array}$ & $\begin{array}{c}\text { Beam } \\
\text { L5 }\end{array}$ & $\begin{array}{c}\text { Section } \\
\text { L5-1 }\end{array}$ & $\begin{array}{c}\text { Fiber } \\
3\end{array}$ \\
\hline Stiffness damage & 0.769 & 0.896 & 0.882 & 0.951 & 0.951 \\
$\gamma_{i+1}^{i}$ & - & 0.120 & 0.249 & 0.554 & 0.425 \\
$\gamma_{i}^{1}$ & - & 0.120 & 0.030 & 0.017 & 0.007 \\
\hline
\end{tabular}

a quantitative way. Obviously, this analysis method is very helpful to design a new structure.

\section{Conclusions}

In order to explore the multilevel damage mechanism of the RC framed structure, five structural levels (structure level, storey level, member level, section level, and material level) were proposed as the multilevel analysis objects. Based on the generalized deformation equivalent principle, a generalized stiffness damage model is proposed for every structural level. The stiffness damage for each structural level can be calculated by integrating material stiffness damage. Furthermore, an impact factor was proposed to reflect quantitatively the damage correlations between different levels. As an example, a single-span 12-storey RC framed model was analyzed using this method. The results show that the multilevel damage analysis method can evaluate accurately the damage correlations between different levels. It should be very useful for the damage assessment and design of structures.

\section{Data Availability}

The data used to support the findings of this study are available from the corresponding author upon request.

\section{Conflicts of Interest}

The author declares that there are no conflicts of interest.

\section{Acknowledgments}

The author acknowledges the support of the National Natural Science Foundation of China under Grant no. 51778284 and the China Postdoctoral Science Foundation under Grant no. 2016M591836.

\section{References}

[1] W. B. Kratzig, I. F. Meyer, and K. Meskouris, "Damage evolution in reinforced concrete members under cyclic loading," in Proceedings of 5th International Conference on Structural Safety and Reliability, vol. 2, pp. 795-802, San Francisco, CA, USA, August 1989.

[2] H. Sucuoglu and A. Erberik, "Energy-based hysteresis and damage models for deteriorating systems," Earthquake Engineering and Structural Dynamics, vol. 33, pp. 69-88, 2004.

[3] E. Erduran and A. Yakut, "Component damage functions of reinforced concrete frame structures," Engineering Structures, vol. 29, no. 9, pp. 2242-2253, 2007.
[4] H. Banon and D. Veneziano, "Seismic safety of reinforced concrete members and structures," Earthquake Engineering and Structural Dynamics, vol. 10, no. 2, pp. 179-193, 1982.

[5] J. F. Wang, C. C. Lin, G. L. Lin, and C. H. Yang, "Storey damage identification of irregular buildings based on earthquake records," Earthquake Spectra, vol. 29, no. 3, pp. 963985, 2013.

[6] Y. J. Park and A. H. S. Ang, "Mechanistic seismic damage model for reinforced concrete. Journal of Structural Engineering," ASCE, vol. 111, no. 4, pp. 722-739, 1985.

[7] A. Sharifi, M.-R. Banan, and M.-R. Banan, "A strainconsistent approach for determination of bounds of ductility damage index for different performance levels for seismic design of RC frame members," Engineering Structures, vol. 37, pp. 143-151, 2012.

[8] G. S. Kamaris, G. D. Hatzigeorgiou, and D. E. Beskos, "A new damage index for plane steel frames exhibiting strength and stiffness degradation under seismic motion," Engineering Structures, vol. 46, pp. 727-736, 2013.

[9] E. DiPasquale and A. S. Cakmak, "Detection and assessment of seismic structural damage," Technical Report NCEER87-0015, National Center for Earthquake Engineering Research, State University of New-York, Buffalo, NY, USA, 1987.

[10] J. Lubliner, J. Oliver, S. Oller, and E. Oate, "A plastic-damage model for concrete," International Journal of Solids and Structures, vol. 25, no. 3, pp. 299-329, 1989.

[11] L. Jie and Y. Weizhong, "Elastoplastic stochastic damage constitutive law for concrete," China Civil Engineering Journal, vol. 42, no. 2, pp. 31-38, 2009.

[12] GB 50010-2010, Code for Design of Concrete Structures, China Architecture and Building Press, Beijing, China, 2010, in Chinese.

[13] J. Lemaitre, "Evolution of dissipation and damage in metals, submitted to dynamic loading," in Proceedings of the I.C.M.1, Kyoto, Japan, 1971.

[14] A. D. Hanganu, E. Onate, and A. H. Barbat, "A finite element methodology for local/global damage evaluation in civil engineering structures," Computers and Structures, vol. 80, no. 20-21, pp. 1667-1687, 2002.

[15] C. J. Shao, Y. H. Wu, and Y. H. Qian, "Evolution of nonlinear seismic damage of concrete bridge structure," China Journal of Highway and Transport, vol. 19, no. 5, pp. 41-45, 2006, in Chinese.

[16] H. Z. Shen, C. H. Zhang, and L. H. Kou, "Performance-based seismic damage assessment model for concrete gravity dams," Journal of Tsinghua University, vol. 47, no. 12, pp. 2114-2118, 2007, in Chinese.

[17] J. Yue, J. Qian, and D. E. Beskos, “A generalized multi-level seismic damage model for RC framed structures," Soil Dynamics and Earthquake Engineering, vol. 80, pp. 25-39, 2016.

[18] J. Oliver, M. Cervera, S. Oller, and J. Lubliner, "Isotropic damage models and smeared crack analysis of concrete," Proceedings of the 2nd ICCAADCS, vol. 2, pp. 945-958, Pineridge Press, Zell Am See, Austria, 1990.

[19] J. C. Simó and J. W. Ju, "Strain and stress based continuum damage models-part I formulation," International Journal of Solids and Structures, vol. 23, no. 7, pp. 281-301, 1987.

[20] State Key Laboratory of Disaster Reduction in Civil Engineering of Tongji University, Benchmark Test of a 12-Story Reinforced Concrete Frame Model on shaking table, Tongji University, Shanghai, China, 2004, in Chinese.

[21] ABAQUS, Abaqus Analysis User's Manual, Version 6.4, Hibbitt, Karlsson \& Sorensen, Inc., Pawtucket, RI, USA, 2003. 


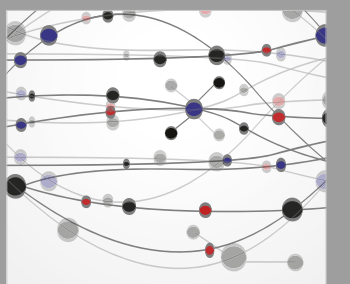

The Scientific World Journal
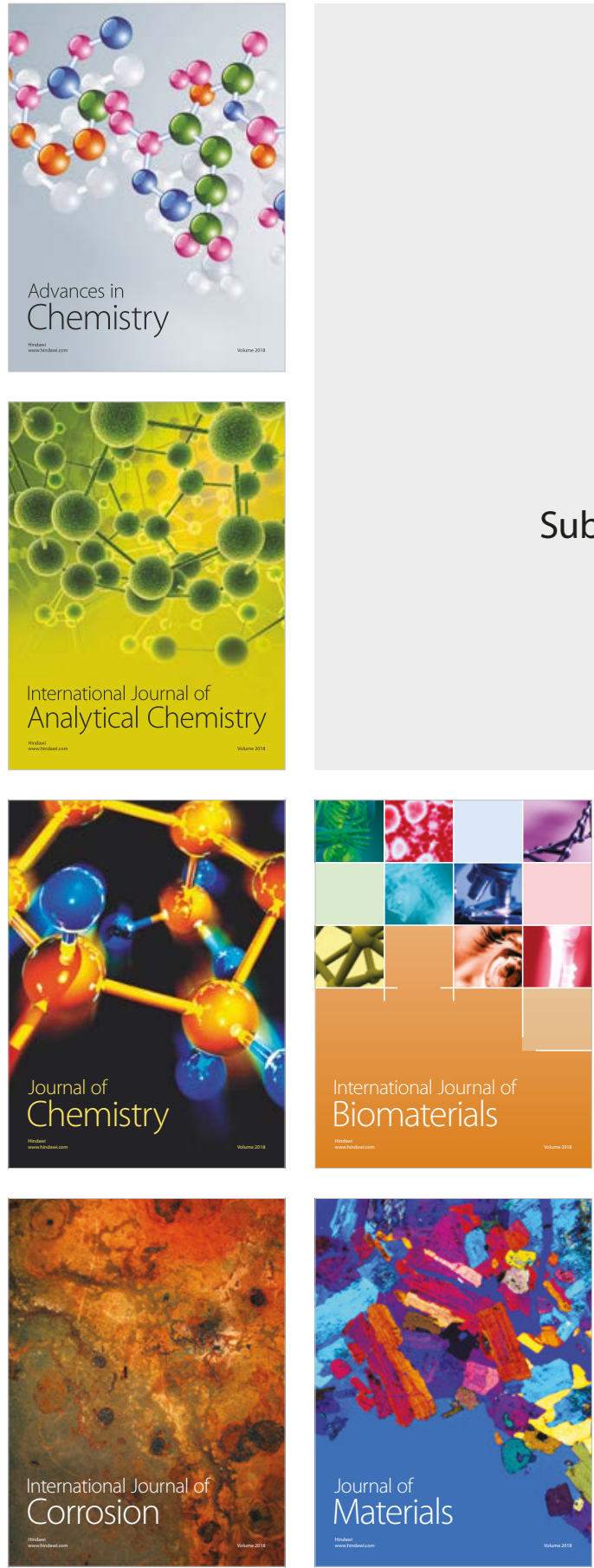

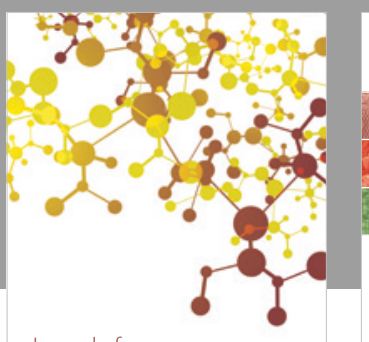

Journal of

Applied Chemistry
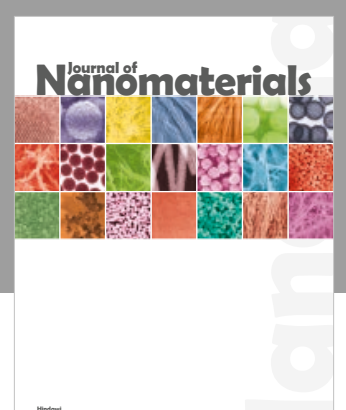

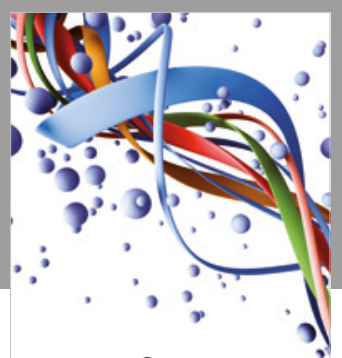

Scientifica

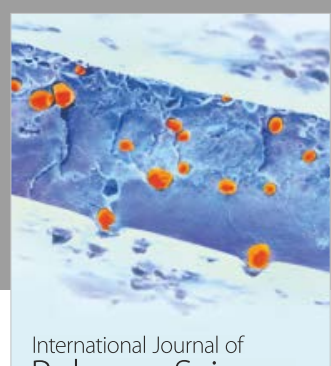

Polymer Science

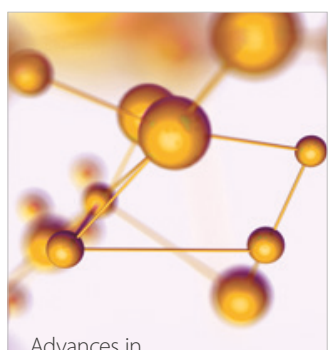

Physical Chemistry
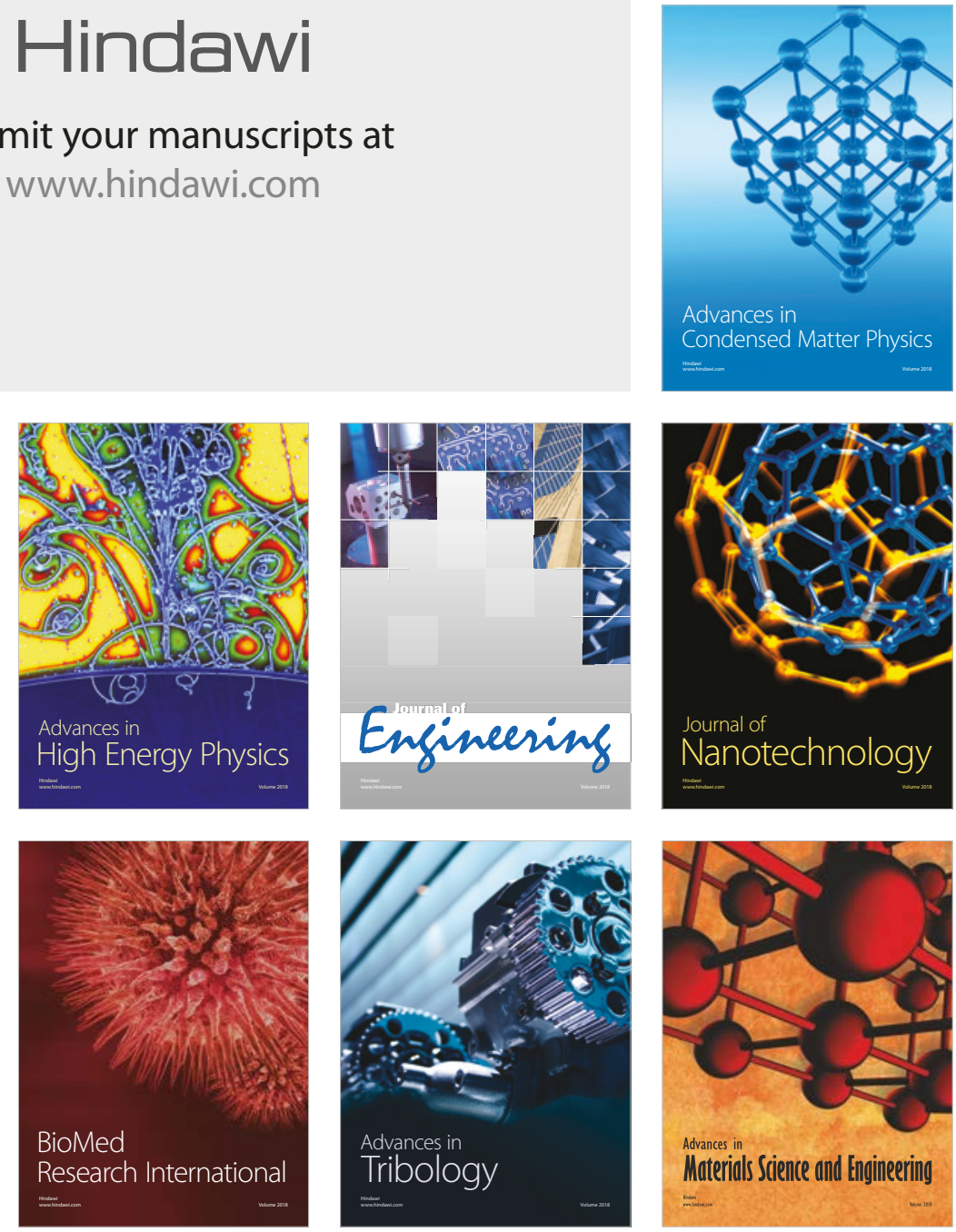